\title{
Prosodic patterns in child speech
}

\author{
Roksolana Mykhaylyk \\ Center for Advanced Study in Theoretical Linguistics (CASTL), University of \\ Tromsø, Norway \\ https://doi.org/10.36505/ExLing-2011/04/0025/000194
}

\begin{abstract}
This paper presents an experimental study contributing to the issue of prosodysyntax-semantics interaction in child speech. The data from 12 3-4-year-old children acquiring Ukrainian have been analyzed in order to establish main prosodic patterns associated with different semantic types of SVO and SOV sentences. The results show that the children are mostly adult-like in the prosodic realization of post-verbal object pronouns, but often apply non-adult-like prosodic contours to the sentences with contextually-dependent object NPs.
\end{abstract}

Key words: pitch, prosodic contour, scrambling, Ukrainian

\section{Introduction}

It has been established that there is an obvious interaction between prosody, semantics and syntactic structure in adult speech (Vallduvi 1992, Cinque 1993, Selkirk 1995, Zubizarretta 1998, inter alia). In child language, however, the role of prosody has not been clearly defined. Some studies suggest that young children differ from adults in the use of intonation/pitch: i.e., the child variations in the prosodic contours are often due to different emotional and interactional contexts, and not to the semantics or information structure (Behrens \& Gut 2005, Chen \& Fikkert 2007). Other studies (e.g., Chen $2010 \& 2011$ ) show that 4-5-year-olds are able to use intonation to encode informational status of arguments. A specific issue to clarify concerns a prosody-syntax-semantics interaction in intonational languages with a 'flexible' word order since in such languages, scrambling might have the same interpretational effect as prosodic destressing (Neeleman \& Reinhart (1998)).

\section{Ukrainian: Syntax-prosody Interaction}

Prosodic and syntactic properties of Ukrainian interact in an interesting way. The unmarked prosodic structure of Ukrainian is shown in (1) (as defined by Féry et al. (2007)):

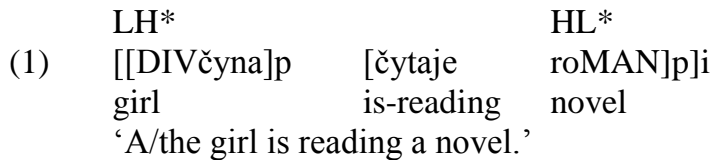

The basic syntactic structure of Ukrainian is SVO. However, pronouns (and other context-dependent elements, such as definite or partitive NPs) usually

ExLing 2011: Proceedings of 4th Tutorial and Research Workshop on Experimental Linguistics, 25-27 May, Paris, France 
must appear in pre-verbal position ((2) \& (4)). This requirement can be circumvented only if the intonation of a sentence is modified (as in (3) \& (5)).
(2) Divčyna roman pročytala. girl novel read 'The girl has read the novel.'
000
(3) Divčyna
PROČYTALA roman. girl read novel
(4) Divčyna joho pročytala.
(5) Divčyna PROČYTALA joho. girl read it girl it read
'The girl has read it.'

This research investigates whether, in cases where children fail to move a contextually-dependent noun or pronoun, they will compensate for this lack of movement by destressing the object and applying the falling pitch accent on the verb, as is shown for adults in Antonyuk-Yudina \& Mykhaylyk (2009). If children are able to establish context relatedness for the direct object, they will apply a distinct prosodic contour to the SVO sentences with the definite/partitive/pronominal objects as compared to the neutral contour associated with the indefinite object in the SVO sentence.

\section{Experiment \\ Method}

Twelve 3-4-year-old monolingual Ukrainian children participated in the experiment. The method was a picture description task, in which the pictures and questions were designed to elicit particular types of nouns/pronouns. The design was based on Mykhaylyk (2010), and the conditions matched those presented in Antonyuk-Yudina \& Mykhaylyk's (2009) study on adult Ukrainian. The goal was to identify the intonation preferred for two types of syntactic structures (i.e., SVO and SOV) in four contexts triggering use of definite, partitive, indefinite or pronominal direct object. For example, in the Definite/Pronominal Context, there was a car in one picture and Kangaroo with the same car and a set of tools in another picture, and the expected responses were either 'Kangaroo her/the car is fixing' or 'Kangaroo IS FIXING her/the car'. Target sentences were analyzed acoustically and labeled using ToBI labeling conventions (Pierrehumbert 1980, Silverman et al. 1992). The key principles of the child data analysis were identical to the analysis of adult results: the common types of prosodic contours were identified, and the group results for the object stress and the verb pitch type were analyzed. 


\section{Results}

The results show that the children distinguish several types of prosodic contours and are able to use them in appropriate contexts. The basic SVO structure with an indefinite object has an unmarked prosodic contour (as in (1)). On the other hand, the SVO structure with a pronominal direct object has the strongest falling pitch accent realized on the verb $\left(\mathrm{H}^{*}+\mathrm{L}\right)$, while the object is prosodically destressed (see Fig.1), exactly as in the adult results (see Antonyuk-Yudina \& Mykhaylyk 2009).

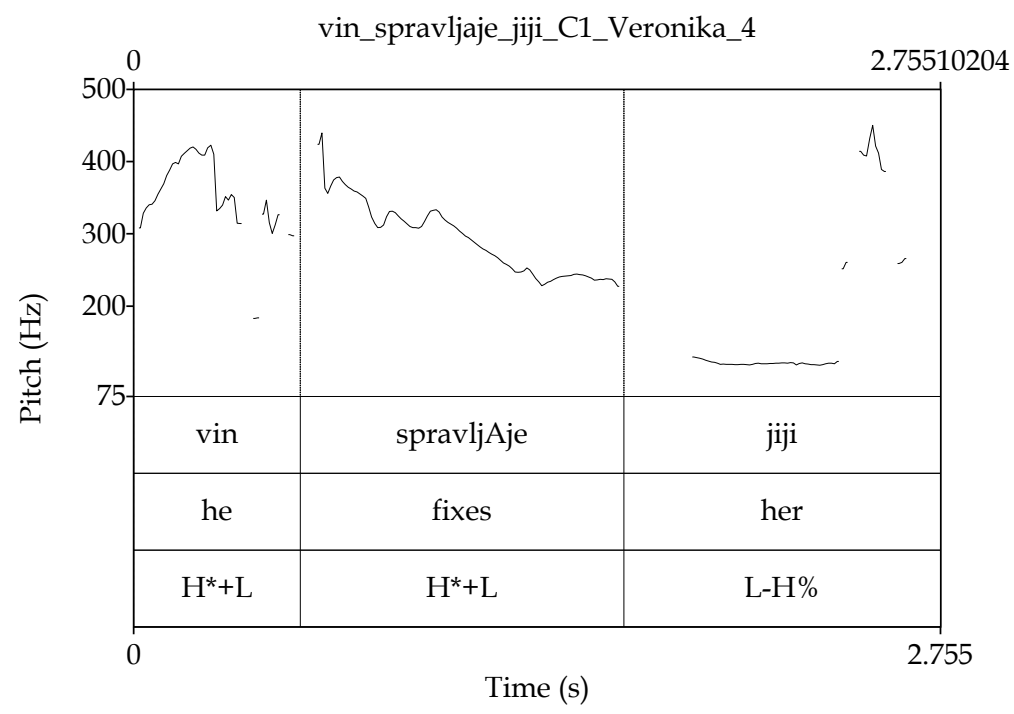

Figure 1. Prosodic contour of an SVO structure with a pronominal object

The children exhibited more variability in SVO sentences with contextually-dependent full NPs. When they dropped a subject and used a two-word structure with a definite object in a postverbal position, their prosody was mostly adult-like: with a falling pitch accent on the verb and a destressed object. However, the three-word structures often had unmarked prosody regardless of the context.

The total group results confirm that the children behave mostly adult-like in never stressing indefinite direct objects in the basic SVO structure (cf. Table 1 and Table 2). They also closely approximate adults by destressing pronouns at $75 \%$ (cf. 100\% for adults in Table 2), but are less adult-like in the prosodic realization of sentences with other context-dependent direct objects. As shown in Table 1, the child prosody of sentences with definite and partitive objects differs considerably from the adult prosody in similar semantic contexts (Table 2). 
Table 1. SVO structures with four types of direct objects: Children, $\%$.

\begin{tabular}{|l|c|c|c|c|}
\hline \hline & Pronominal object Definite objectPartitive objectIndefinite object \\
\hline Destressed object & 75 & 50 & $\mathbf{7 5}$ & $\mathbf{0}$ \\
\hline Falling pitch on verb & $\mathbf{1 0 0}$ & 56 & 50 & 50 \\
\hline
\end{tabular}

Table 2. SVO structures with four types of direct objects: Adults (From Antonyuk-Yudina \& Mykhaylyk (2009)), \%

\begin{tabular}{|l|c|c|c|c|}
\hline \hline & Pronominal objectDefinite objectPartitive object Indefinite object \\
\hline Destressed object & 100 & 87 & $\mathbf{7 5}$ & $\mathbf{0}$ \\
\hline Falling pitch on verb & $\mathbf{1 0 0}$ & 100 & 88 & 25 \\
\hline \hline
\end{tabular}

While the child data exhibit a clear contrast between the stress placement on the direct object (definite and partivive objects are destressed more often $(50 \% \& 25 \%)$ than indefinite objects $(0 \%))$, there is no such contrast for the prosodic realization of the verb. The definite and partitive contexts do not trigger use of the falling pitch on the verb more often than indefinite contexts (56\%, 50\% and 50\%, respectively). It is important to mention, however, that none of the children's prosodic contours could be considered 'incorrect', but some of them just differed from those normally used by adults.

\section{Conclusion}

These findings are comparable to Chen (2011): both studies show that children at the age of 4 are already sensitive to the context-prosody correlation. However, the children's prosodic patterns appear to be more variable than the adult patterns in similar semantic contexts. While in this study the child and adult data could not be compared directly due to the difference in methodology, established patterns deserve further investigation.

\section{References}

Antonyuk-Yudina, S.,R. Mykhaylyk. 2009. Prosodic effects in word order: Evidence from Ukrainian. Presentation at NELS-40, MIT.

Chen, A. 2011. Tuning information packaging: Intonational realization of topic and focus in child Dutch. Journal of Child Language. Available on CJO 2006.

Chen, A., Fikkert P. 2007. Intonation of early two-word utterances in Dutch. In Trouvain, J., William, J.B. (eds.), Proc. of 16th ICPhS. Pirrot GmbH, Dudweiler.

Féry, C., Paslawska, A., Fanselow, G. 2007. Nominal split constructions in Ukrainian. Journal of Slavic Linguistics 15 (1), 3-48.

Mykhaylyk, R. 2010. Optional object scrambling in child and adult Ukrainian. PhD dissertation, Stony Brook University.

Neeleman, A., Reinhart, T. 1998. Scrambling and the PF interface. In Butt, M., Geuder, W. (eds.), The projection of arguments: Lexical and compositional factors, 309-353. Stanford, CA: CSLI Publications.

Zubizarreta, M.L. 1998. Focus, prosody, and word order. Camb., MA: MIT Press. 